\title{
Changes in the Long-Term Geophysical Eruptive Precursors at Piton de la Fournaise: Implications for the Response Management
}

\section{OPEN ACCESS}

Edited by:

Nicolas Fournier,

GNS Science, New Zealand

Reviewed by:

Alessandro Tibaldi,

Università degli studi di Milano

Bicocca, Italy

Dmitri Rouwet,

Istituto Nazionale di Geofisica e

Vulcanologia (INGV), Italy

*Correspondence:

Aline Peltier

peltier@ipgp.fr

tPresent Address:

Nicolas Villeneuve Laboratoire GéoSciences Réunion, Université de La Réunion, Institut de

Physique du Globe de Paris, Sorbonne Paris Cité, CNRS, Saint Denis, France

Specialty section:

This article was submitted to Volcanology,

a section of the journal Frontiers in Earth Science

Received: 29 March 2018 Accepted: 05 July 2018 Published: 25 July 2018

Citation:

Peltier A, Villeneuve N, Ferrazzini V Testud S, Hassen Ali T, Boissier P and Catherine $P$ (2018) Changes in the Long-Term Geophysical Eruptive Precursors at Piton de la Fournaise: Implications for the Response

Management. Front. Earth Sci. 6:104. doi: 10.3389/feart.2018.00104

\begin{abstract}
Aline Peltier ${ }^{1 *}$, Nicolas Villeneuve ${ }^{1 \dagger}$, Valérie Ferrazzini ${ }^{1}$, Séverine Testud ${ }^{2}$, Theo Hassen Ali ${ }^{2}$, Patrice Boissier ${ }^{2}$ and Philippe Catherine ${ }^{1}$

1 Institut de Physique du Globe de Paris, Sorbonne Paris Cité, Observatoire Volcanologique du Piton de la Fournaise, Université Paris Diderot, UMR 7154 CNRS, La Plaine des Cafres, France, ${ }^{2}$ UFR Sciences et Techniques, Université Jean Monnet de Saint Etienne, Saint Etienne, France
\end{abstract}

Anticipating eruptions early enough to give warning to authorities is one of the main goals in volcanology. However, identifying and providing unequivocal identification on volcano reawakening remain challenging issues, mostly when unrests are sudden or undetectable. At the Piton de la Fournaise volcano, a clear increase in both the seismicity and the ground displacements are systematically observed a few days/weeks before eruptions, and appear as clear eruptive precursors. Here a systematic study of these long-term precursors demonstrates the changes in their intensity, duration, and time of appearance during 1998-2017 (43 eruptions), directly linked to the influence of the pre- and post-summit caldera formation (April 2007) and to changes in the deep magma refilling process since 2016. These changes in the precursors were not without consequence on the early alert to the authorities, with some false alerts and late alerts. It is thus of prime importance for crisis management to bear in mind the possibility of these rapid changes and that of sudden volcanic unrest with little warnings, to be able to take the most appropriate decisions, in particular raising the level of alert or lifting it totally. The findings of this study have enabled the relevant authorities to improve the alert chain protocol, and scientists to communicate more efficiently with the decision-makers.

\footnotetext{
Keywords: Eruptive precursors, Piton de la Fournaise, volcano hazards and risks, volcano monitoring, crisis management
}

\section{INTRODUCTION}

Volcanic eruptions threaten communities, given their potential to cause fatalities and economic loss. Therefore, the expectation of society in volcano science is to provide local emergency management authorities and decision makers with timely forecasts of imminent volcanic eruptions. However, forecasting a volcano's behavior and being able to unambiguously construe volcanic unrest as eruption precursor remains complex. This applies especially when signals of renewed volcanic activity arise suddenly or are not even detected. On September 27, 2014, Mount Ontake (Japan) erupted without evident long-term precursors, killing 63 persons (including 6 missing). No long-term ground deformation and only 2 weeks of unusual seismic activity had been recorded before the eruption (Kato et al., 2015).

On the Piton de La Fournaise volcano (a hot spot volcano on La Réunion Island, Indian Ocean; Figures 1A,B), eruptive precursors, such as increase in volcano-tectonic seismicity, 
edifice inflation, and degassing, are now well identified, occurring on two time scales, which enable the OVPF (Observatoire Volcanologique du Piton de la Fournaise: Piton de la Fournaise Volcano Observatory) to warn local authorities of (1) high probability of an eruption in the following weeks/months (signs of reservoir pressurization; "Vigilance" alert level), and (2) high probability of an eruption in the following minutes/hours (signs of final dike propagation toward the surface; "Alert level 1-Imminent eruption”). Warning levels are issued within the framework of the ORSEC (Organisation de la Réponse de SEcurité Civile: Civil Security Response) "Piton de la Fournaise Volcano" plan, which is an emergency plan set up by the department responsible for the protection of the population in the event of unrest or activity of Piton de la Fournaise. Within this plan, OVPF is the first actor in the response chain; it informs the Prefecture (decentralized administrative service of the French State) via the Etat Major de Zone et de Protection Civile de l'Ocean Indien: EMZPCOI (Indian Ocean Zone and Civil Protection Headquarters) in the event of any change in volcanic activity and proposes to change the alert levels (Harris et al., 2017). The final decision to change the alert levels provided by the plan is the sole responsibility of the Préfet (head of the Préfecture). The Préfecture then communicates with other actors (town councils, gendarmerie (local police), central authorities, institutions and the media). Early warning in the event of the threat of an eruption is possible thanks to both a dense monitoring network implemented in the field by OVPF and recent advances in our knowledge of the volcano, making Piton de la Fournaise one of the world's best-studied basaltic volcanoes. Recent studies have enabled a better understanding of its feeding system, with evidence of several variably connected reservoirs distributed over ca. $11 \mathrm{~km}$ below the summit, its dynamics and their associated signals (e.g, Battaglia et al., 2005; Peltier et al., 2009; Brenguier et al., 2012; Got et al., 2013; Di Muro et al., 2014; Lengliné et al., 2016).

In spite of well-established patterns of eruptive precursors, major changes have appeared in the activity of Piton de la Fournaise-and in the associated long-term eruptive precursors-during the two last decades, notably as regards the links with the major collapse of the main summit crater in April 2007. For instance in 2016-2017, eruptions were preceded by totally absent or weak long-term precursors, and even for one eruption (September 11-18, 2016), this led to late communication with the Prefecture on the volcanic unrest state, going directly from "No alert" to "Alert 1-Imminent eruption" and by passing the intermediate "Vigilance" alert level.

A good knowledge of the long-term eruptive precursors and their evolution over time is of prime importance to be able to issue early and efficient warning and react to volcanic unrest, giving reliable information to authorities. It is against this background that the present study was set. We systematically studied the long-term seismicity and volcanic edifice deformation (duration and intensity) preceding each eruption during the period 1998-2017 (43 eruptions) and we studied the possible influence of the pre- and post-caldera formation on these eruptive precursors.

\section{METHODS}

Since December 1979, the Piton de la Fournaise volcano has been monitored by the OVPF, which depends on the IPGP (Institut de Physique du Globe de Paris) and is now one of the most efficiently and closely monitored volcanoes in the world, thanks to 100 or so instruments (seismometers, GNSS receivers: Global Navigation Satellite System, tiltmeters, extensometers, gas stations, optic and infra-red cameras) implemented in the field. From 1980 to the end of 2017, 68 eruptions were anticipated and followed by the OVPF. All these networks made it possible to identify three main precursors: volcano-tectonic seismicity, volcano deformation, degassing. These precursors occur on two time-scales linked to two distinct in-depth processes: (1) in the long term (weeks/months): slow edifice inflation (less than $3 \mathrm{~mm}$ per day), $10-100 \mathrm{VT}$ earthquakes per day, and $\mathrm{CO}_{2}$ ground degassing, linked to the refilling of the shallow magma system and its pressurization; and (2) in the short term (tens of minutes/hours): strong rapid ground deformation and a swarm of shallow (above sea level; asl) volcano-tectonic events (referred to as "seismic crisis"), linked to the final dike injection toward the surface (e.g, Peltier et al., 2009; Roult et al., 2012; Schmid et al., 2012; Boudoire et al., 2017; Figure 2). The Piton de la Fournaise volcano is a low degassing volcano making it challenging to monitor volcanic degassing on its flanks. The first permanent gas stations were implemented only in 2007, explaining why the first systematic degassing precursors have been evidenced at the Piton de la Fournaise only recently (Boudoire et al., 2017). Because of the late installation of the gas stations (after the 2007 collapse), the gas precursors are disregarded in this study and we have only focused on the evolution of the long-term seismic and ground deformation precursors. We made a systematic analysis of the pre-eruptive seismicity and deformation for the time series of 100 and 15 days (in order for the findings not to be affected by eruptions occurring too close to each other), preceding eruption onsets over the period 1998-2017 (Table 1). Since we studied the late stages of eruption triggering, we took into consideration only the shallow (0-2 km asl) volcano-tectonic seismicity below the summit, shown as daily rates, and the summit deformation shown here as baseline (i.e., line length between two GNSS stations) variations; both being related to the shallow magma system pressurization (Peltier et al., 2009; Roult et al., 2012; Figures 2, 3, Table 1). In these time series, we did not consider the "seismic crises" and the strong rapid ground deformation preceding the eruptions by a few minutes/hours and linked to the final dike propagation toward the surface from the shallowest magma reservoir, located at about $1.5-2.5 \mathrm{~km}$ in depth (e.g., Peltier et al., 2009; Di Muro et al., 2014). The GNSS network being implemented only since 2004, in Figure $\mathbf{2 b}$ we also indicate the evolution of the FORX extensometer-opening component, in order to have an overview of the global edifice deformation throughout the period considered.

\section{ERUPTIVE ACTIVITY BETWEEN 1998 AND 2017}

Our study starts in 1998, the date of renewed eruptive activity after almost 6 years of rest. This date corresponds to the starting 


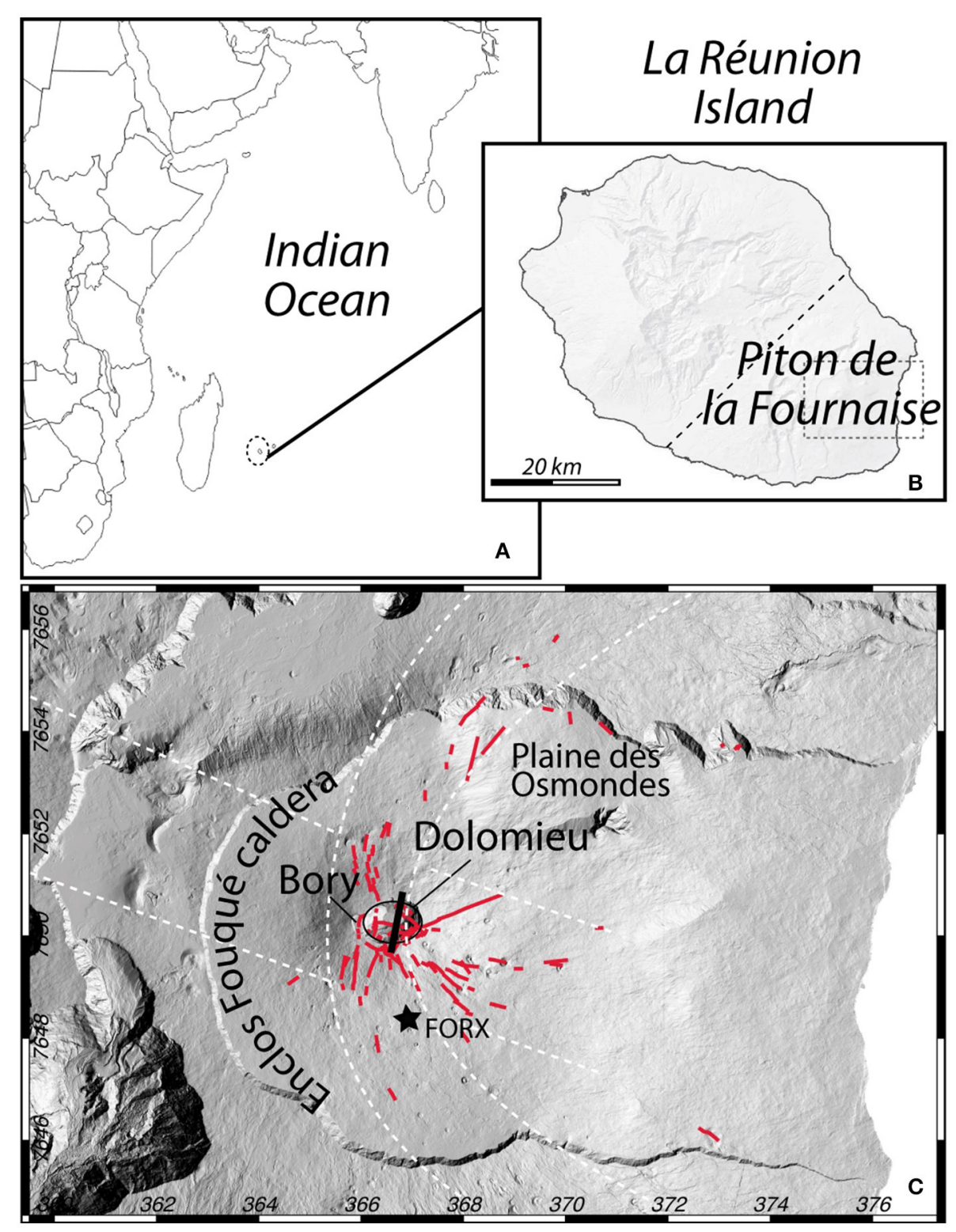

FIGURE 1 | Location of (A) La Réunion in the Indian Ocean and of (B) Piton de la Fournaise on La Réunion Island. (C) Zoom on the Enclos Fouqué caldera, where 97\% of the current Piton de la Fournaise eruptive activity occurred. The location of the eruptive fissures between 1998 and 2017 and the rift zones are shown in red and white, respectively. The black line crossing the Dolomieu crater represents the baseline shown in Figure 2.

point of new intense eruptive activity, but also to a densification of the monitoring network, with, notably, new seismometers and the implementation of a dense permanent GNSS network in 2004. This high eruptive activity and the new monitoring tools allowed a better characterization of the eruptive precursors.

Except for a late eruptive fissure opening at the end of the 1998 eruption, all eruptions of the 1998-2017 period occurred inside the Enclos Fouqué caldera (Figure 1C), like 97\% of the recent eruptive activity (Villeneuve and Bachèlery, 2006). This caldera is fully uninhabited but visited by more than 100000 people by year [source: Office Nationale des Forêts (Forestry Commission)].
From 1998 to 2017, we distinguish 3 periods of eruptive activity: 1998-2007, 2008-2010, 2014-2017, separated by two key events, the Dolomieu summit caldera collapse (340 m depth) during the major March-May 2007 eruption (about $240 \mathrm{Mm}^{3}$ of emitted lavas, i.e., about 10 times that of an average Piton de la Fournaise eruption), and a rest period of 41 months in 2011-2014 (e.g., Peltier et al., 2009, 2010, 2016; Roult et al., 2012; Staudacher et al., 2016; Figure 2, Table 1): (1) 1998-2007: $451 \mathrm{Mm}^{3}$ of cumulated emitted lavas (868 days of activity; lava flow rate of about $6 \mathrm{~m}^{3} / \mathrm{s}$ ), a period marked by continuous refilling of the shallow magma plumbing system, and by signs 


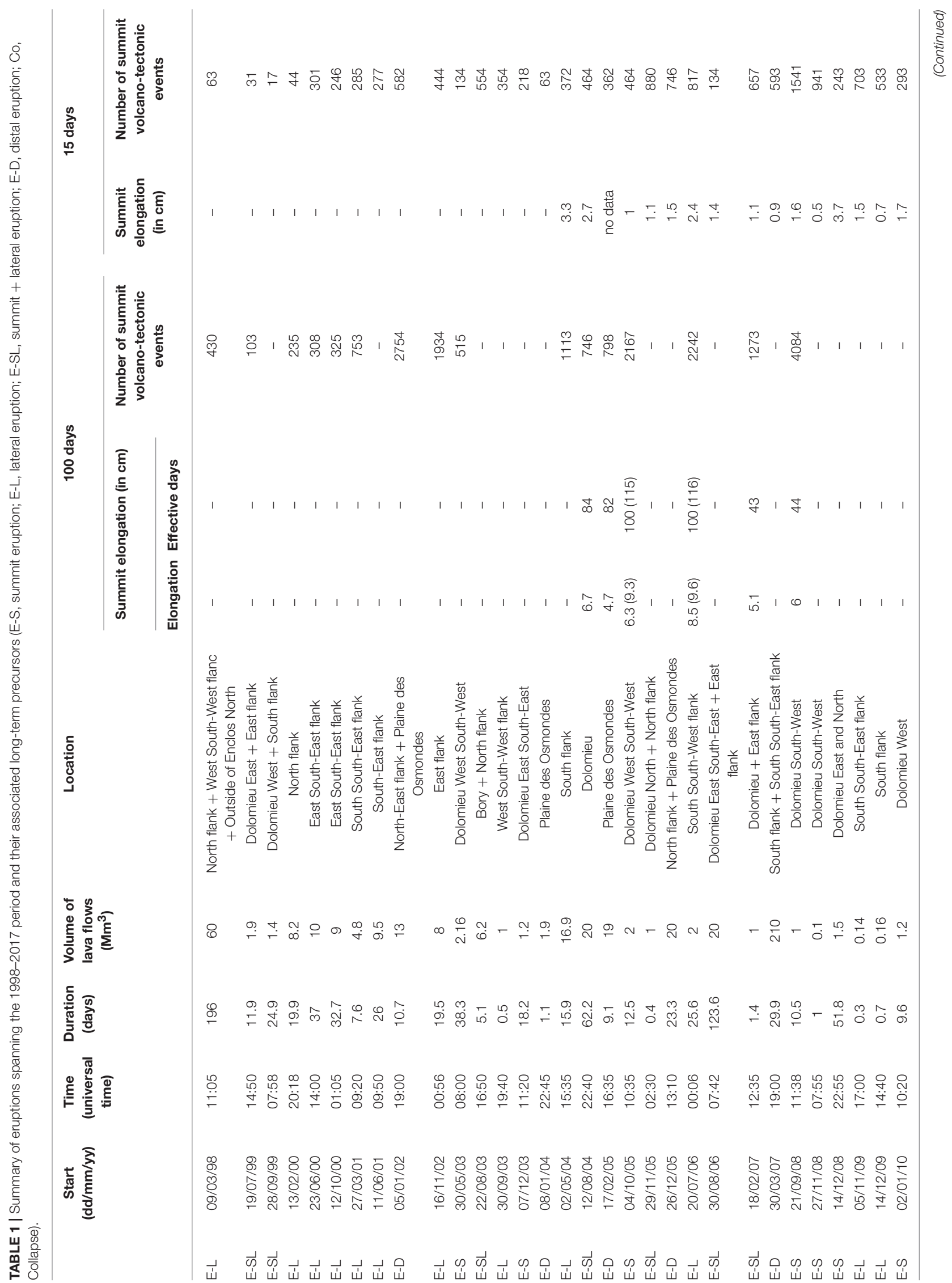




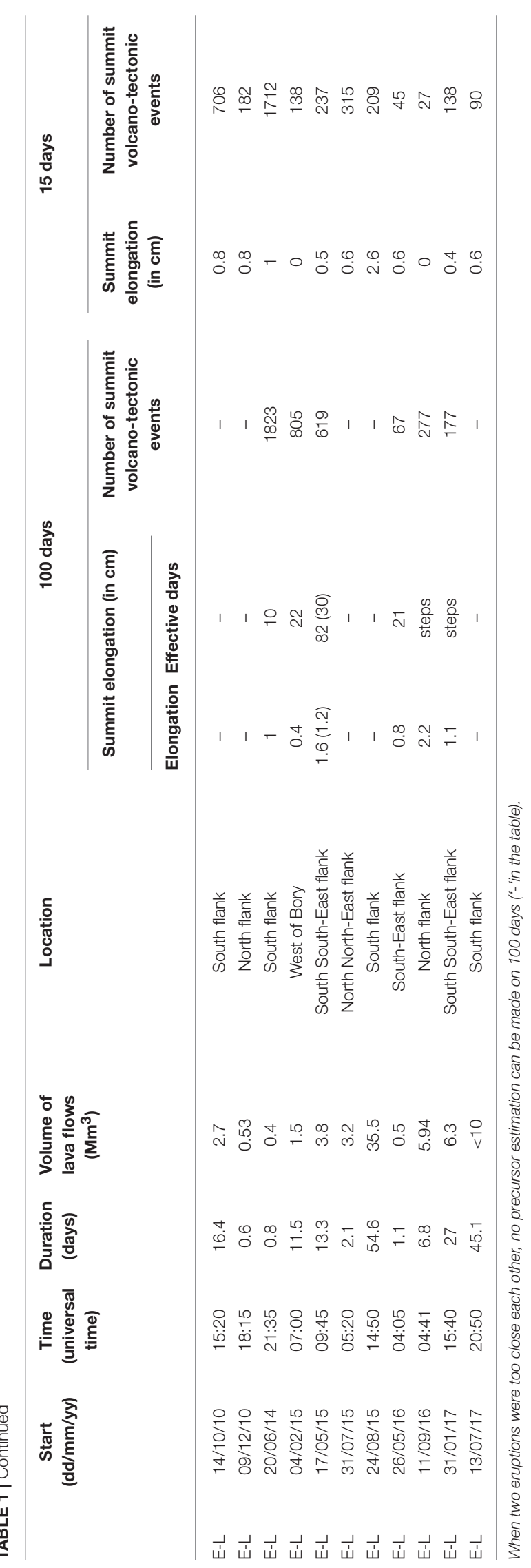

of short-term eruptive cycles culminating in more important distal eruptions (e.g., Peltier et al., 2009; Staudacher et al., 2016); (2) 2008-2010: $7.3 \mathrm{Mm}^{3}$ of cumulated emitted lava (91 days of activity; lava flow rate of about $0.9 \mathrm{~m}^{3} / \mathrm{s}$ ), a period marked by a change in the eruptive activity after the 2007 collapse with only low-volume summit or near-summit eruptions (eight) and many aborted magma intrusions (eight). Roult et al. (2012) attribute this change to stress changes in the volcano edifice after the collapse and a concomitant decrease in volumes in magma input; (3) 2014-2017:57 $\mathrm{Mm}^{3}$ of cumulated emitted lavas (166 days of activity; lava flow rate of about $4 \mathrm{~m}^{3} / \mathrm{s}$ ), a period marked by a renewal of the eruptive activity, with flank eruptions only and numerous long-lasting eruptions ( 3 eruptions of a duration $>20$ days; Table 1).

\section{RESULTS}

On the whole, a clear increase in both the seismicity and ground displacements (global edifice inflation) is systematically observed a few days/weeks before the eruptions, and these appear as clear eruptive precursors (Table 1, Figure 2). The summit volcanotectonic seismicity is of low magnitude ( $90 \%$ of the events have magnitude $<1$ ) and is mainly located below the summit craters, at a depth comprised between 500 and $2,000 \mathrm{~m}$ asl (Massin et al., 2011; Lengliné et al., 2016). The source at the origin of the ground deformation has been attributed to a pressurized magma reservoir located at a depth of around $0-1,500 \mathrm{~m}$ above sea level (Peltier et al., 2009, 2016), just below the summit volcano-tectonic seismicity. In spite of the similarities in the location of the seismicity and of the pressure sources from one pre-eruptive period to the other, the intensity and the time of occurrence of these long-term eruptive precursors vary according to the periods considered, namely the three periods of activity previously distinguished.

(1) 1998-2007: long-term seismicity and inflation appeared about 100 days before the eruption (Table 1; Figures 2, 3); with an almost steady state of continuous pre-eruptive edifice inflation (only short-term deflation was recorded following the major distal eruptions; Figure 2b); and throughout the period, an evolution toward an increase in the long-term pre-eruptive seismicity was observed with an average of about 40 earthquakes in 1998-2000 vs. 550 in 2006-2007, during the 15 days preceding an eruption (Figure 4). The increase in seismicity and continuous inflation clearly begins in 2000 (Figure 2b; Peltier et al., 2009).

(2) 2007-2010: pre-eruptive long-term seismicity and inflation appeared later, compared to the 1998-2007 period, about 40-50 days before the eruption (Figure 3); the longterm pre-eruptive seismicity included some strong seismic swarms with more than 100 earthquakes per day not followed by eruptions (Figure 3). The long-term pre-eruptive edifice inflations were weaker than previously observed (low volume of magma involved at depth originating low volume of erupted lava during this period, Table 1) and between these phases a major continuous summit deflation was recorded (summit contraction of $\sim 3 \mathrm{~cm} / \mathrm{y}$; Figure 2). 


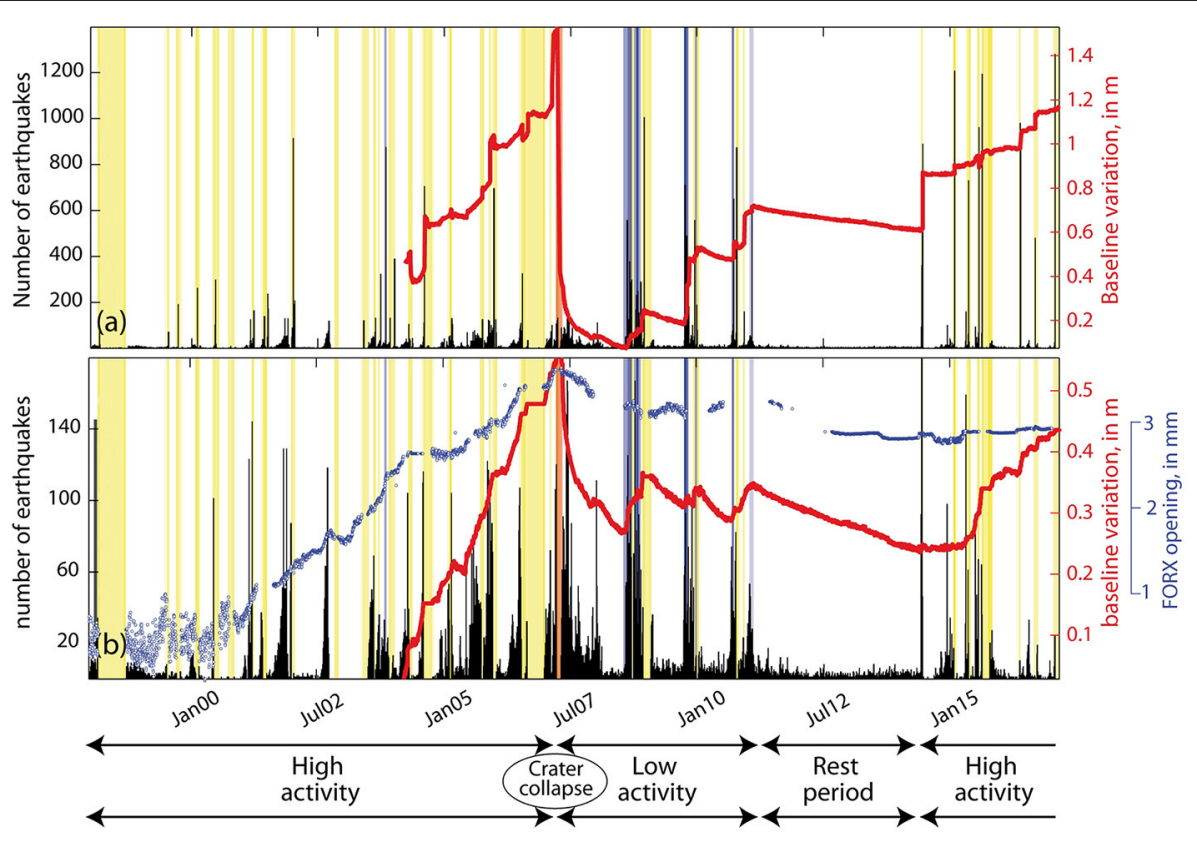

FIGURE 2 | (a) Time series covering 1998-2017, with the daily number of earthquakes (in black) and the distance change (baseline variation in red) between two summit GNSS stations (see location in Figure 1C). The yellow, blue and red shaded areas represent the eruptive, intrusive and the March-April 2007 eruptive periods, respectively. Note that the first continuous GNSS were implemented only in 2004. (b) The same as (a) but in this graph, the rapid and strong displacements and seismicity linked to dike injections preceding eruptions by a few tens of minutes have been removed to avoid saturating the $y$-scale and better highlight the long-term inter-eruptive signal. In blue: opening component variation (in $\mathrm{mm}$ ) of the FORX extensometer (see location in Figure 1C). An increase in the signal corresponds to a fracture opening. As for the seismicity and GNSS plots, the rapid and strong signals inked to dike injections preceding eruptions by a few tens of minutes have been removed.

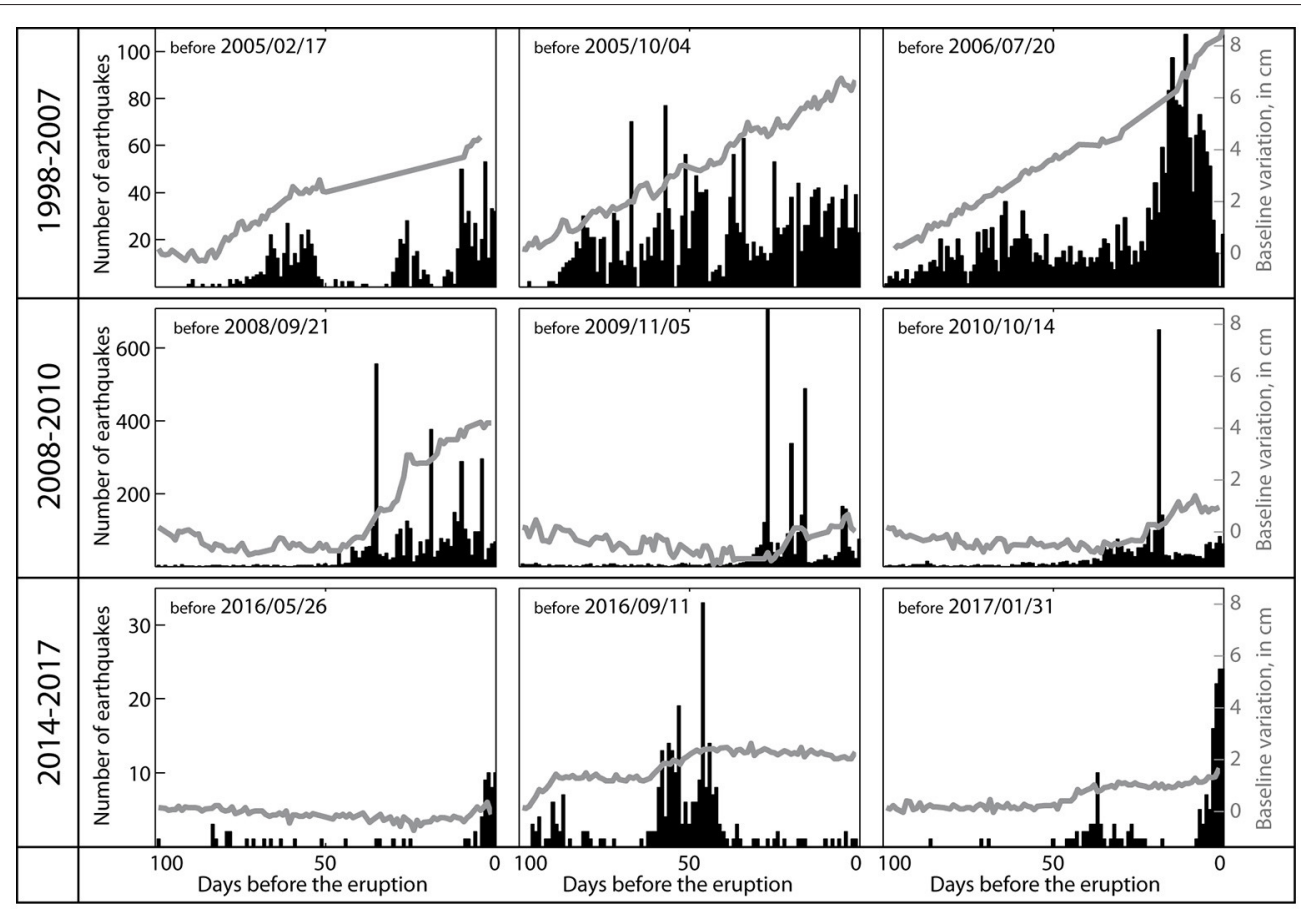

FIGURE 3 | Zoom on nine pre-eruptive periods. For each example, the daily number of earthquakes (in black) and the distance change (baseline variation in gray) between two summit GNSS stations (see location in Figure 1C), the 100 days preceding the onset of the eruption are shown. 


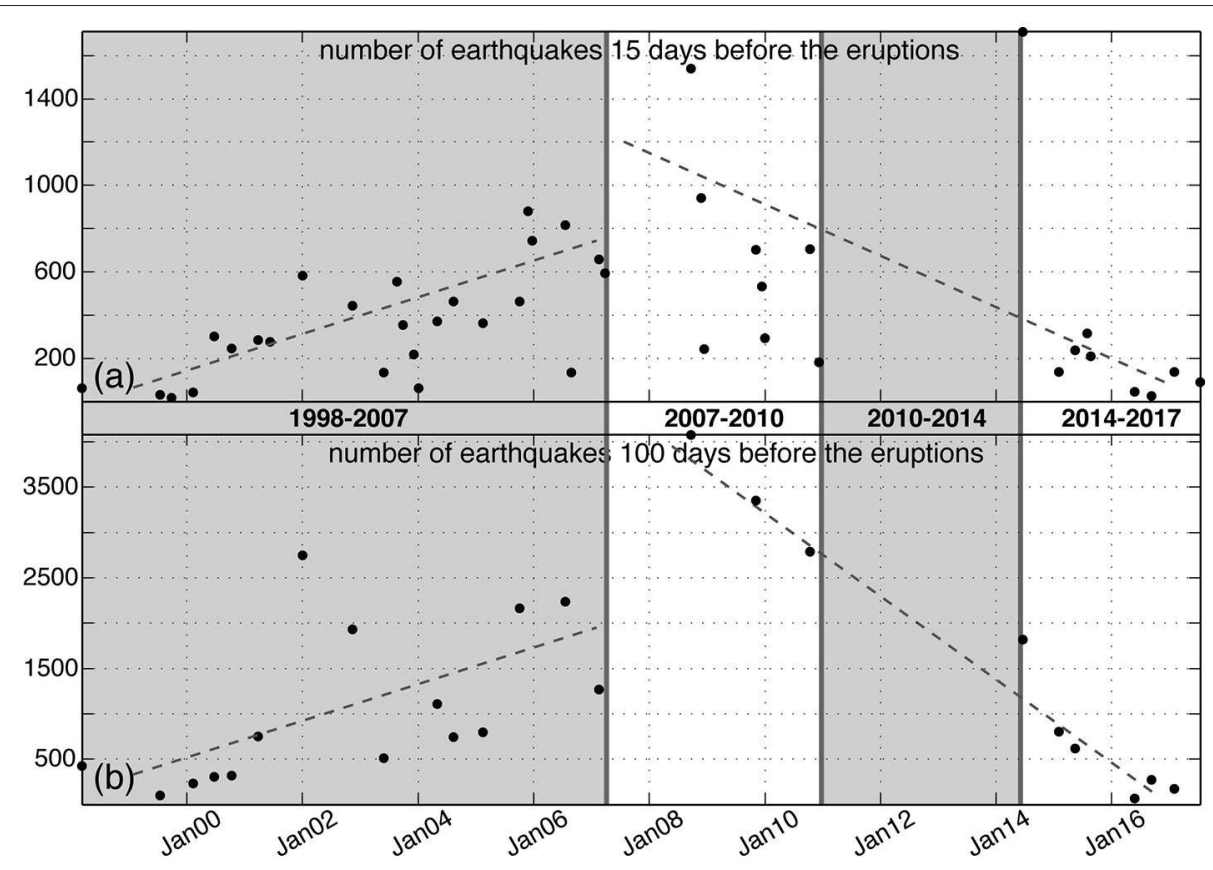

FIGURE 4 | Evolution of the daily number of earthquakes (a) 15 and (b) 100 days preceding the eruptions. In (b), only the eruptions separated in time by more than 100 days were taken into consideration, in order to avoid being impacted by short-term precursors related to previous final dike injections. The shaded areas represent the eruptive periods described in the text.

Between 2011 and June 2014, a period of volcanic rest with no eruption occurred and was characterized by edifice deflation and weak summit seismicity (Figure 2).

(3) 2014-2017: less intense pre-eruptive long-term seismicity and inflation; the renewal of eruptive activity on June 20, 2014 was preceded by only 11 days of precursors. Apart from 2 days of strong seismicity, the level of seismicity and deformation remained low (1712 earthquakes including 360 and 687 during two seismic swarms on June 13 and 17, respectively; and $1 \mathrm{~cm}$ of summit elongation; Table 1).

For the following 2015 eruptions (four events), the almost continuous inflation was observed once more, but at a lower rate compared to the two first periods (summit elongation of $0.2-0.4$ $\mathrm{mm} / \mathrm{d}$ vs. 0.6-1 mm/d in 2004-2007; Table 1; Peltier et al., 2016). And in 2016-2017, pre-eruptive long-term inflation became discontinuous, and seismicity was lower (a few dozen events during the 15 days preceding an eruption; Table 1) and appeared only one (September 11, 2016 eruption) to ten (January 30, 2017; May 26, 2016) days before the eruption. We can note that 40-60 days before the eruptions of September 2016, January 2017 and July 2017, 1-2 weeks of seismicity increase were observed during stages of short-term inflation renewal (Figure 3).

In short, the long-term pre-eruptive seismicity and deformation (linked to the plumbing system pressurization) increased progressively from 1998 until the major eruption of March-May 2007, during which the Dolomieu crater collapsed, and then progressively decreased and appeared later and later (from about 100 days before the eruption in 1998-2007 to about 15 days in 2014-2017; Figure 3). After the collapse of the Dolomieu crater, in 2008-2010, even though the time of occurrence of the seismicity was shorter, seismicity remained high, taking the form of a large number of seismic crises not followed by eruptions (Figure 3).

\section{DISCUSSION}

\section{Influence of the Pre- and Post-caldera Formation on the Long-Term Pre-eruptive Precursors}

Between 1998 and 2017, major changes occurred in the Piton de la Fournaise activity and in the associated long-term preeruptive precursor, reflecting major changes in the dynamism and stress state of the volcano. This is especially well visible on Figure 4, where the number of long-term pre-eruptive earthquakes increased before the collapse and then decreased after. The events of March-May 2007 (a major eruption and the Dolomieu crater collapse) appeared as key events in the recent history of the volcano, and seem to have influenced both the volcano activity and its eruptive precursors (Peltier et al., 2010; Staudacher, 2010; Massin et al., 2011; Roult et al., 2012).

From 1998 to 2007, the sustained activity of the volcano was maintained by a continuous filling up of the plumbing system, evidenced by near continuous summit inflation (Peltier et al., 2009). This led to a progressive weakening of the medium (Got et al., 2013) at the origin of the increase in seismicity throughout the period (Figure 4), even though part of the accumulated stress had been released during distal eruptions. Indeed, Got et al. 
(2013) showed that the eruptive cycles spanning the 2000-2007 period were linked to nonlinearity in the stress state of the edifice, as the strong eastern flank plastic displacement during distal eruptions enabled the stress accumulated during an eruptive cycle to be release and to enable the start of a new cycle. In spite of this release, the long-term pre-eruptive seismicity remained high and continued to increase throughout the period, and the continuous and long-term damage in the medium culminated with the April 2007 crater caldera collapse. The observed increase in seismicity between 2000 and 2007 could thus be a very long-term precursor of the in-depth collapse initiation due to the progressive weakening of the medium, notably linked with the continuous edifice inflation; and the triggering of the final collapse would occur due to the fast draining of the reservoir during the beginning of the March-April 2007 eruption (Michon et al., 2011).

After this major eruption, important changes occurred in the volcano and on its surface, consequences of the draining of the shallow reservoir and damage to the shallow plumbing system and its surrounding medium, due to the crater caldera collapse. Between 2008 and 2011, 8 low-volume eruptions and 8 aborted magma intrusions occurred (Figure 2), mostly in the upper part of the volcano. The long-term pre-eruptive seismicity remained high, but mostly occurred during seismic swarms accompanied by ground deformation (magma intrusions) or not (stress release in the medium). The seismic swarms not accompanied by ground deformation were not linked to magma migrations in depth but rather to stress changes and readjustments in the volcanic edifice following the collapse. The large number of aborted intrusions and the location of the eruptions inside or very close to the summit were related to the low magma volume and overpressure involved in depth, sometimes too low for the magma to reach the surface. The main continuous summit deflation observed between eruptive phases confirms that no deep magma refilling occurred during these periods, and that the main contribution of the deformation field during this period was the edifice destabilization and the large withdrawal of the magma reservoir in April 2007 (Figure 3b). This deflation continued between 2011 and 2014, also a period during which no sign of deep refilling was observed.

It was not until 2014 that a more "typical" activity, close to the one observed in 1998-2000, was again observed at Piton de la Fournaise, with increasingly late appearance of long-term eruptive precursors (from about 100 days before the eruption in 1998-2007 to about 15 days in 2014-2017; Figure 3), and less and less long-term pre-eruptive seismicity reaching a level similar in 2017 to the one observed in 1998-2000 (Figure 4). This shows a progressive decrease in the influence of damage and stress readjustment linked to the collapse.

\section{Influence of the Deep Magma Refilling on the Long-Term Pre-eruptive Precursors}

Since 2016, the well-established long-term pre-eruptive continuous inflation pattern previously observed-both before the 1998-2007 eruptions and the 2008-2010 eruptions-has disappeared, replaced by a discontinuous inflation trend
(Figure 3) probably reflecting discontinuous deep magma pulses entering into the shallow plumbing system.

This new deforming process of the volcano makes it more difficult to anticipate eruptions in the long-term, as the pressure building up and the stress accumulation inside the reservoir occurred in steps (discontinuous magma accumulation), and not continuously as previously observed (Figures $\mathbf{2 b}, \mathbf{3}$ ). The time between two stages can be long and the last stages can be very short in duration, as observed in September 2016, when the final dike propagation was preceded by only limited warning signs (Figure 3). After two periods of edifice inflation not followed by an eruption (Figure 3; around May 27-June 13 and July 9-27, 2016), 1 month of summit deflation led the Prefecture to change the alert level, replacing "Vigilance" by "No alert" on September 5,2016 , only 6 days before the onset of the September 11, 2016 eruption. Fortunately, the short-term precursors (seismic crisis and strong deformation) associated with the final dike propagation toward the surface led the observatory to alert the Prefecture $56 \mathrm{~min}$ before the onset of the eruption, and the alert level passed directly from "No alert" to "Alert 1-Imminent eruption," bypassing the intermediate "Vigilance" alert level.

\section{Implications for the Communication System}

Volcanoes are complex and highly non-linear natural systems. Their unrest and activity, as well as their associated signals, can thus quickly change. These quick changes can have consequences on the efficiency of the alert chain for the authorities, with some false alerts and late alerts. Indeed, whatever the natural phenomena studied (geoscience or meteorology), early warnings, but also caution, are necessary in the communication chain. This is even truer when the first communication comes from an operational research center, such as an observatory. Within the ORSEC "Piton de la Fournaise Volcano" plan, the role of the Observatory is to communicate to the authorities any changes (increase or decrease) in volcanic activity and in the number and intensity of eruptive precursors, via real-time and 24/7 volcano monitoring. The authorities (via decisions taken by the Préfet) decide any changes to be made in the alert level issued and transmit this information to the public institutions directly concerned and to the media. Any change in the alert level triggers the ORSEC "Piton de la Fournaise Volcano" plan that applies a dedicated protocol for the services involved (gendarmerie (local police), Office Nationale des Forêts (Forestry Commission), civil protection), and can have consequences on access to the volcano, which can thus, notably, affect tourism in this sector. As specified in the ORSEC "Piton de la Fournaise Volcano" plan, during the "Vigilance" alert level, access to the volcano summit is permitted but restricted to the official track (this is particularly restrictive for commercial guided tours that cannot take other paths), whereas during "Alert level 1-Imminent eruption," access is prohibited and visitors (and, possibly, the threatened population) are quickly evacuated on foot or by helicopter, weather conditions permitting. In view of these elements and the difficulties of access to the volcano and evacuations related to the site morphology (mainly in terms of intervention time), 
in the event of "Alert level 1-Imminent eruption," any change in the alert level is an important decision, which must be carefully assessed. This requires an efficient communication chain between each actor (the observatory, authorities, and media), and necessitates sending reliable information from the observatory. Recent changes in the Piton de la Fournaise plumbing system feeding pattern and the associated precursors (time of appearance (Figure 3), number (Figure 4, Table 1), and intensity) have made this communication more complicated. On the one hand, this has led to over-evaluations (with, notably, false alerts), and, on the other hand, to late issue of information (e.g., the September 11, 2016 eruption, see section Influence of the Deep Magma Refilling on the Long-Term Pre-Eruptive Precursors), with a risk of loss of credibility for the observatory. One example is the February 4, 2015 eruption, for which the first subtle precursors appeared in November 2014. OVPF alerted the authorities, who issued the "Vigilance" alert level. On December 1 , in the absence of any eruption, the alert was lifted by the Prefecture. On December 4, following several observations released by the OVPF, the Prefecture again issued the alert level, before lifting it again in early January 2015. The February 4, 2015 eruption began after a 1-month period of relative calm (which followed magma and stress accumulation during November and December) and a short-term seismic crisis. Because of the bad weather, only a few people were at the volcano at the time of the eruption, and only one 70-year-old man was in difficulty as a result of the eruption. He was on one of the official tracks and less than $100 \mathrm{~m}$ from the lava flow front, which blocked his way back. Fortunately, he was rescued by helicopter just before nightfall, after walking $7 \mathrm{~h}$ in very difficult conditions. His presence was authorized because no alert had been issued at the time of his departure to the volcano (a few hours before the onset of the eruption). With operational feedback, notably concerning crisis management in February 2015 and September 2016, the authorities, and even the population, maintain a very high level of confidence in the observatory. They are now aware of the complexity of the volcano's periods of reawakening and of the impossibility of accurate assessment as regards the precise timing of a coming eruption, and of the necessity of being cautious during any level alert changes, as well as during press releases.

Piton de la Fournaise is not the only volcano where behavior change has led to delay or failure in communication with local authorities. Before the eruption of September 27, 2014 at Mount Ontake, the volcano warning level had not been changed, because the number of low-frequency earthquakes detected was much lower than those recorded for the 2007 eruption (Yamaoka et al., 2016), leading to a catastrophic loss of lives.

It is thus of prime importance for crisis management and decision-making that scientists and politicians bear in mind the possibility of these rapid changes in a well-established pattern for a specific volcano and of the possibility of sudden volcanic unrest with little warning; particularly since communication between the actors involved (scientists, politicians and then the general public) can be a long process.

\section{CONCLUSIONS}

Our detailed study shows that the intensity, duration and onset of long-term eruptive precursors changed quickly at Piton de la Fournaise between 1998 and 2017. These changes were linked to changes in the internal stress of the volcano before and after the April 2007 summit caldera, and after the period of calm of 2011-2014.

- From 1998 to 2007: the progressive seismicity increase throughout this period of continuous inflation (continuous deep refilling) could be a very long-term precursor of the indepth collapse onset due to the progressive weakening of the medium.

- From 2007 to 2010: long-term pre-eruptive seismicity remained high and this reveals stress changes and readjustments in the volcanic edifice following the collapse. Deflation during inter-eruptive periods showed that no significant deep magma refilling occurred.

- From 2014 to 2017: the renewed eruptive activity in 2014, after 41 months of rest was very sudden (11 days of longterm precursors). Since 2016, discontinuous injections of deep magma have refilled the shallow plumbing, leading to rapid final dike propagations preceded by few warning signs.

Volcanoes are highly non-linear systems, and these changes in the precursors were not without consequence on the early alert to the authorities, with some false alerts and late alerts. The findings of this study have enabled the relevant authorities to improve the alert chain protocol, and scientists to communicate more efficiently with the decision-makers.

\section{AUTHOR CONTRIBUTIONS}

$\mathrm{AP}$ and NV contributed to the design and implementation of the research. VF analyzed the seismic data. ST and TH contributed to the compilation of the database. AP, NV, PB, and PC contributed to the deformation data analyses.

\section{ACKNOWLEDGMENTS}

Data used in this paper were collected by Observatoire Volcanologique du Piton de la Fournaise/Institut de Physique du Globe de Paris (OVPF/IPGP), and can be found in this portal: http://volobsis.ipgp.fr. Part of this work was funded by Agence Nationale de la Recherche under contract ANR-16-CE04-0004-01 (SlideVOLC). We are grateful for helpful proof-reading from Nicole Richter, and thorough reviews by Dmitri Rouwet, Alessandro Tibaldi, the associate editor Nicolas Fournier and the chief editor Valerio Acocella. This is IPGP contribution number 3951. 


\section{REFERENCES}

Battaglia, J., Ferrazzini, V., Staudacher, T., Aki, K., and Cheminée, J. L. (2005). Pre-eruptive migration of earthquakes at the Piton de la Fournaise volcano (Réunion Island). Geophys. J. Int. 161, 549-558. doi: 10.1111/j.1365-246X.2005.02606.x

Boudoire, G., Di Muro, A., Liuzzo, M., Ferrazzini, V., Peltier, A., Gurrieri, S., et al. (2017). New perspectives on volcano monitoring in a tropical environment: continuous measurements of soil $\mathrm{CO}_{2}$ flux at Piton de la Fournaise (La Réunion Island, France). Geophys. Res. Lett. 44. 8244-8253. doi: 10.1002/2017GL 074237

Brenguier, F., Kowalski, P., Staudacher, T., Ferrazzini, V., Lauret, F., Boissier, P., et al. (2012). First results from the UnderVolc high-resolution seismic and GPS network deployed on Piton de la Fournaise Volcano. Seismol. Res. Lett. 83,97-102. doi: 10.1785/gssrl.83.1.97

Di Muro, A., Metrich, N., Vergani, D., Rose, M., Armienti, P., Fougeroux, T., et al. (2014). The shallow plumbing system of Piton de la Fournaise volcano (La Reunion Island, Indian Ocean) revealed by the major 2007 caldera-forming eruption. J. Petrol. 55, 1287-1315. doi: 10.1093/petrology/egu025

Got, J. L., Peltier, A., Staudacher, T., Kowalski, P., and Boissier, P. (2013). Edifice strength and magma transfer modulation at Piton de la Fournaise volcano. J. Geophys. Res. 118, 5040-5057. doi: 10.1002/jgrb.50350

Harris, A., Villeneuve, N., Di Muro, A., Ferrazzini, V., Peltier, A., Coppola, D., et al. (2017). Effusive Crises at Piton de la Fournaise 2014-2015: a review of a multi-national response model. J. Appl. Volcanol. 6:11. doi: 10.1186/s13617-017-0062-9

Kato, A., Terakawa, T., Yamanaka, Y., Maeda, Y., Horikawa, S., Matsuhiro, K., et al. (2015). Preparatory and precursory processes leading up to the 2014 phreatic eruption of Mount Ontake, Japan. Earth Planets Space 67:111 doi: 10.1186/s40623-015-0288-x

Lengliné, O., Duputel, Z., and Ferrazzini, V. et al., (2016). Uncovering the hidden signature of a magmatic recharge at Piton de la Fournaise volcano using small earthquakes. Geophys. Res. Lett. 43, 4255-4262. doi: 10.1002/2016GL068383

Massin, F., Ferrazzini, V., Bachèlery, P., Nercessian, A., Duputel, Z., and Staudacher, T. (2011). Structures and evolution of the plumbing system of Piton de la Fournaise volcanoinferred from clustering of 2007 eruptive cycle seismicity. J. Volcanol. Geotherm. Res. 202, 96-106. doi: 10.1016/j.jvolgeores.2011.01.008

Michon, L., Massin, F., Famin, V., Ferrazzini, V., and Roult, G. (2011). Basaltic calderas: collapse dynamics, edifice deformation and variations of magma withdrawal. J. Geophys. Res. 116, B03209. doi: 10.1029/2010JB007636

Peltier, A., Bachèlery, P., and Staudacher, T. (2009). Magma transfer and storage at Piton de la Fournaise (La Réunion Island) between 1972 and 2007: a review of geophysical and geochemical data. J. Volcanol. Geotherm. Res. 184, 93-108. doi: 10.1016/j.jvolgeores.2008.12.008
Peltier, A., Beauducel, F., Villeneuve, N., Ferrazzini, V., Di Muro, A., Aiuppa, A., et al. (2016). Deep fluid transfer evidenced by surface deformation during the 2014-2015 unrest at Piton de la Fournaise volcano. J. Volcanol. Geotherm. Res. 321, 140-148. doi: 10.1016/j.jvolgeores.2016.04.031

Peltier, A., Staudacher, T., and Bachèlery, P. (2010). New behaviour of the Piton de La Fournaise volcano feeding system (La Réunion Island deduced from GPS data: influence of the 2007 Dolomieu crater collapse. J. Volcanol. Geotherm. Res. 192, 48-56. doi: 10.1016/j.jvolgeores.2010.02.007

Roult, G., Peltier, A., Taisne, B., Staudacher, T., Ferrazzini, V., Di Muro, A., and the OVPF group (2012). A new comprehensive classification of the Piton de la Fournaise eruptions spanning the 1986-2011 period. Search and analysis of eruption precursors from a broad-band seismological station. J. Volcanol. Geotherm. Res. 241-242, 78-104. doi: 10.1016/j.jvolgeores.2012.06.012

Schmid, A., Grasso, J. R., Clarke, D., Ferrazzini, V., Bachèlery, P., and Staudacher, T. (2012). Eruption forerunners from multiparameter monitoring and application for eruptions time predictability (Piton de la Fournaise). J. Geophys. Res. 117, B11203. doi: 10.1029/2012JB009167

Staudacher, T. (2010). Field observations of the 2008 summit eruption at Piton de la Fournaise (Ile de La Réunion) and implications for the 2007 Dolomieu collapse. J. Volcanol. Geotherm. Res. 191, 60-68. doi: 10.1016/j.jvolgeores.2010.01.012

Staudacher, T., Peltier, A., Ferrazzini, V., Di Muro, A., Boissier, P., Catherine, P., et al. (2016). "Fifteen years of intense eruptive activity (1998-2013) at Piton de La Fournaise volcano (La Réunion): a review," in Active Volcanoes of the Southwest Indian Ocean: Piton de la Fournaise and Karthala, eds P. Bachèlery, J. F. Lénat, A. Di Muro, L. Michon (Berlin: Active volcanoes of the world Springer), 139-170.

Villeneuve, N., and Bachèlery, P. (2006). Revue de la Typologie des Eruptions au Piton de la Fournase, Processus et Risqué Volcaniques Associés. Cybergeo. Available online at: http://cybergeo.revues.org/index2536.html

Yamaoka, K., Geshi, N., Hashimoto, T., Ingebritsen, S. E., and Oikawa, T. (2016). Preface of the special issue "The phreatic eruption of Mt. Ontake volcano in 2014”. Earth Planets Space 68:175. doi: 10.1186/s40623-016-0548-4

Conflict of Interest Statement: The authors declare that the research was conducted in the absence of any commercial or financial relationships that could be construed as a potential conflict of interest.

Copyright (C) 2018 Peltier, Villeneuve, Ferrazzini, Testud, Hassen Ali, Boissier and Catherine. This is an open-access article distributed under the terms of the Creative Commons Attribution License (CC BY). The use, distribution or reproduction in other forums is permitted, provided the original author(s) and the copyright owner(s) are credited and that the original publication in this journal is cited, in accordance with accepted academic practice. No use, distribution or reproduction is permitted which does not comply with these terms. 